\title{
I'm Paying the Time for Someone Else's Crime: Principals and Core Teachers at Rural Middle Schools under Chronic Academic Stress
}

\author{
Jafeth E. Sanchez \\ Janet Usinger \\ Bill W. Thornton \\ William E. Sparkman \\ University of Nevada, Reno
}

Today, many principals are assigned to struggling schools with the mandate to quickly change the academic trajectory of the students. Interviews were conducted to gain an understanding of how principals and core teachers working at rural middle schools under chronic academic stress perceived the increased academic expectations at their schools. Three key findings were revealed: (a) There were misaligned principal and teacher interpretations of efforts to improve the school; (b) there tended to be an ongoing focus on what was wrong with the school; and (c) principals felt they were alone in the process. A discussion of these findings is provided.

Keywords: principals, teachers, rural middle schools, academic stress, educational leadership programs

Accountability and higher academic standards continue to permeate the public educational system in the United States. Current principals and teachers in public schools face increased demands for school improvement as defined by student academic achievement measured by high-stakes tests. In some cases, these demands are federal, requiring formal school turnaround strategies, at which point prescriptive interventions, possible restructuring, and other efforts may occur (U.S. Department of Education, 2006). In other cases, school district leaders may identify and focus on schools under chronic academic stress in efforts to improve school performance to prevent a federal turnaround designation. Regardless of federal or district initiated pressures to improve school performance, it is not uncommon for principals to be assigned to struggling schools with specific charges to rapidly increase academic achievement, change the culture of the school, and sustain positive results.

Accountability for increased academic achievement focused on high-stakes testing has been the focus in the public K-12 system for several decades. This focus has aimed to keep students academically ready for each subsequent year, with an ultimate path to high school graduation. However, recently there has been a shift in the accountability goal beyond high school graduation to college and career readiness. Conley (2010) argued that a college-going culture reflects a pervasive schoolwide belief that all students can enroll and succeed in postsecondary education. Radcliffe and Stephens
(2008) identified various critical components of a college-going culture for school improvement, such as mentoring, use of technology, college visits, and parental involvement. In high-achieving schools, this shift is a matter of raising the academic expectations. In schools that are under chronic academic stress, principals and teachers similarly face increased expectations for turnaround goals. Often times, the creation of a college-going culture may support efforts to close existing academic achievement gaps among students in order to meet those turnaround expectations.

Changing the culture of a school to target improvements in academic achievement can be daunting in any circumstance, but it may be particularly challenging for principals assigned to rural schools for several reasons. Specifically, students living in areas with "pronounced rural poverty and socio-economic diversity [tend] to score lower on the National Assessment of Educational Progress (NAEP) and mandated high stakes achievement tests, and graduate at lower rates than peers in states with less rural poverty and diversity" (Byrd \& Brown, 2012, p. 1). Witherspoon and Ennett (2011) concurred, indicating that students enrolled in rural schools often face greater challenges than their urban and suburban counterparts. Rural schools may have some advantages related to smaller enrollment but may not have the level and variety of resources associated with larger schools. This is particularly the situation when rural schools are located in remote, isolated communities; academic enrichment 
opportunities are frequently limited (Cross \& Dixon, 1998).

The role of the principal in schools under chronic stress is pivotal; principals must balance various leadership functions to implement successful strategies (Finkel, 2012; Lynch, 2012; Waters, Marzano, \& McNulty, 2003). Indeed, principal leadership has been recognized as second only to teaching among variables that impact student learning (Leithwood, Louis, Anderson, \& Wahlstrom, 2004). As instructional leaders, principals must work with all stakeholders to increase a sense of shared ownership of the change process and related desired outcomes (Day, 2007). The need for principals to develop a sense of ownership within the building is required to effectively improve student learning. Establishing shared leadership and a sense of ownership among teachers is essential for sustained, continuous improvement (Simmons, 2011). However, increased expectations and demands can lead to added stress and worry among teachers (Norwood, 2007), so principals must give careful consideration to teacher concerns while still maintaining high expectations for continuous improvement.

High expectations can be fostered through a combination of a clear vision, mission, and a positive school culture that support targeted outcomes. Regardless of school size or type, principals who share leadership efforts, enable collaborative cultures, and develop common values and a shared vision can increase effectiveness (Brown, Finch, MacGregor, \& Watson, 2012). Essentially, "The relationships of principals, as the school leader, strongly and directly affect teachers' attitudes, which define the schooling climate" (Price, 2012, p. 40). This requires principals and teachers to work together to effectively develop and sustain a positive school culture for improvement and overall school change.

\section{Education Change Theory}

The research question investigated in this study was: How do principals and core teachers working at rural middle schools under chronic academic stress perceive the increased expectations? The study was grounded in education change theory, which is considered a relatively new theory that has grown over the last three decades (Glickman, Gordon, \& Ross-Gordon, 2014). As the theory emerged, Evans (1996) explored the human side of school change and focused on strategic and grassroots levels of change. Some of his imperative areas for organizational change were strategies related to the infrastructure for effective change through teams, two-way communication, culture, and leadership as "a critical element of strategic change" (Evans, 1996, p. 67). At a grassroots level, he provided an implementation toolkit for change, which encompassed understanding and communicating changes, goal setting, measuring performance, feedback/coaching, and establishing rewards/recognition (Evans, 1996). More than a decade later, Fullan (2009) continued to expand upon education change theory in combination with leadership and the possible strategies for successful change; he particularly emphasized strategies such as, professional learning communities, shared leadership, and mentoring.

More recently, Glickman et al. (2014) indicated that education change theory is unique because it is "based on the study of actual efforts at school change" and identified several key concepts that tend to be agreed upon by many experts in this area ( $\mathrm{p}$. 353). The concepts are: (1) capacity, (2) commitment, (3) leadership, (4), evolutionary planning, (5) problem solving, (6) support, (7) coherence, and (8) school cultures of continuous improvement. The authors included building capacity for change among teachers and school leadership, along with commitment through ownership in the process. The leadership is shared and distributed, which contributes to evolutionary planning that allows for feedback related to ongoing changes. The feedback and planning may identify problems, but potential problems can be used as opportunities to resolve important issues. Consequently, there is a recognized need for internal and external support, which can be used to facilitate the change effort process, the necessary time to work on the change, and the need to build relationships (Glickman et al., 2014). However, education change theory recognizes that "overload and fragmentation" occur, which results when there are too many change initiatives or when these initiatives are disjointed (Glickman et al., 2014 , p. 357). Thus, a certain amount of coherence with the education change process is needed. This coherence creates consistent change efforts and, ultimately, new cultural norms are developed to create a school culture of continuous improvement.

\section{Study Background}

The culture of academic improvement for college readiness was a goal of a State Early Awareness and Readiness for Undergraduate Programs (GEAR UP) project for each of its middle schools. Therefore, the findings in this study were 
derived from a larger study designed to capture the creation of a college-going culture in 18 urban and rural GEAR UP middle schools. However, the data for this study specifically provides insights about the perceptions that the principals and teachers at six rural middle schools held about changes that were occurring during the first two years (2012-2013 and 2013-2014) of their GEAR UP project. Indeed, Nadelson, Pulska, Moorcroft, Jeffrey, and Woodard (2014) argued that perceptions of reform initiatives held by administrators and teachers are critical indicators to the potential effectiveness of the implementation of reform efforts.

\section{School Contexts}

The six middle schools were situated within rural, often isolated communities; driving distance to general services such as banking, health care, and shopping ranged from 25-90 minutes. The three schools that were closer to general services required shorter travel, but it was only to a slightly larger rural community. The three schools that were farther from general services required longer travel, but this access was to larger metropolitan areas. Along with the distance from general services, the school composition of grade levels also lent an understanding of the rural setting. Two schools were combined schools, grades K-12; two schools were designated elementary schools, but included the middle school grades (K-8); one school had combined grades of 7-12; and only one school was a stand-alone middle school with grades 6-8. Despite the configuration of the school, the focus of this study was on the middle school, specifically grades seven and eight. In considering these unique compositions, the student enrollment in each school was also an indication of the rural setting. Most schools served approximately 20-60 middle school students, with the exception of the stand-alone middle school (6-8), which served approximately 170 students.

The racial/ethnic composition of the student populations varied among the rural middle schools. Three schools were on or in close proximity to Indian Reservations, thus reflecting a primarily Native American student population, and one school was located in an agricultural community with predominately Latino families. The remaining two schools were in communities that served as county seats. One was located near a military depot with employees reflecting many racial/ethnic demographics, but the student population remained predominantly Caucasian; the other school had a $2 \%$ increase in Latino students during the two years of data collection, but still reflected a Caucasian majority. Each school qualified for federal Title I funds. Three schools had free and/or reduced lunch (FRL) percentages from $60 \%$ to $75 \%$; the remaining three schools had FRL percentages from $92 \%$ to $100 \%$. The communities where the schools were located reflected low-educational attainment of the adult population, with a history of minimal enrollment in postsecondary education.

All schools had experienced chronic academic stress, as the schools had been identified as lowperforming schools through the State's high-stakes tests for several years. At the time of this study, the State was in the final stages of implementing a new School Performance Framework, which was a shift from the Annual Yearly Progress (AYP) model associated with No Child Left Behind (NCLB) to a growth model. The State School Performance Framework used to measure academic progress was based on four performance indicators: (1) the Student Growth Percentile, which considered students' growth over time on state assessments; (2) the status measure of achievement, which was based on performance on a single administration of the state test to assess students who met or exceeded standards; (3) the Adequate Growth Percentiles, which considered the reductions in achievement gaps based on the percent of students who met achievement targets; and (4) another indicator, typically a measure of the student average daily attendance. Using these four indicators, an index score was developed and represented the school's academic progress with a maximum score of 100 .

This index score determined the middle school academic classification, which was divided into five score ranges corresponding with star ratings. At the time of the study, there were five star ratings as follows: index score lower than $32=$ one star, index score $32-49=$ two stars, index score 50-67 = three stars, index score $68-76=$ four stars, and index score of 77 or higher $=$ five stars. Schools with the lowest star ratings equated to low academic progress and vice versa. Schools with a 1- or 2-star rating required engagement with external leadership (e.g., school district leadership) for support in school improvement. Schools with a 3 -star rating had negotiated flexibility with the district in decisionmaking; in other words, more school-level autonomy was gained with higher star ratings. 
Table 1

Schools and their Star Rating over Three Academic Years

\begin{tabular}{lccc}
\hline School & $\begin{array}{c}\text { 2011-2012 } \\
\text { (Baseline Year) }\end{array}$ & $\begin{array}{c}\text { 2012-2013 } \\
\text { (Study Year 1) }\end{array}$ & $\begin{array}{c}\text { 2013-2014 } \\
\text { (Study Year 2) }\end{array}$ \\
\hline School 1 & 2-Star & 2-Star & 3-Star \\
School 2 & 1-Star & 1-Star & 2-Star \\
School 3 & 3-Star & 3-Star & 3-Star \\
School 4 & 1-Star & 3-Star & 2-Star \\
School 5 & 1-Star & 1-Star & Not Rated \\
School 6 & 1-Star & 1-Star & 2-Star \\
\hline
\end{tabular}

The new growth model was in place after the conclusion of the 2011-2012 school year, so academic results from that year were used as baseline data, and results from 2012-2013 and 2013-2014 were used to determine each middle school's continuing academic standing. Three schools received a 1-star rating for two consecutive years (2011-2012 and 2012-2013). In the following year (2013-2014), two of those schools increased to a 2star rating and the third was identified as having too small of a sample size to receive a rating. Both schools that increased in their star rating continued to be classified as being in need of improvement. One school received two consecutive 2-star ratings, improving to a 3-star rating during 2013-14.

Although it earned a star increase, it was still identified as needing substantial improvement. One school received a 3-star rating during all three school years. It was a combined elementary/middle school; the elementary school was at a 1-star level for all three years. One school earned an increase in its star rating, from a 1 -star rating to a 3 -star rating from 2011-2012 to 2012-2013, but the rating dropped to a 2-star rating during 2013-2014. Although three of the six schools earned a star increase, all schools in the study required engagement with district leadership and other external partners (e.g., WestEd) to increase achievement and overall school improvement. See Table 1 for details.

In summary, each of the six public, rural middle schools demonstrated some similar and unique school contexts. All schools were situated in rural communities with limited access to general services. The ethnic/racial composition of students varied at each school but shared the characteristic of small student enrollments. All schools had Title I funding, high FRL percentage rates, and poor academic progress. Each school also had star ratings that required some form of district leadership support.

\section{Method}

\section{Participants}

Twenty-four participants were interviewed for this study. Half of the participants were school leaders. The other half were teachers in core academic subjects.

School leaders. All principals/lead teachers and assistant principals of the six middle schools during the time of the study (2012-2013 and 2013-2014 school years) were recruited to participate in interviews. In total, 12 middle school leaders were interviewed: nine principals, two lead teachers who served as principals, and one assistant principal. Eleven individuals who served as principals were assigned to the six rural middle schools during 20122013 and 2013-2014. Two of these individuals held contracts as lead teachers, but were asked to fulfill the principal role for all or part of the 2012-2013 academic year; one had been brought out of retirement to fill the vacant position and went back into retirement at the conclusion of the school year; the other lead teacher officially accepted the principalship at the start of 2013-2014. One middle school (a combined K-12 school) had an assistant principal; this leader was included in the study because of his district-assigned role in providing leadership at the middle school level. Of the total 12 school leaders, 2 were female and 10 were male. All but one leader were Caucasian; one leader was Native American. Five of the 12 principals were veteran with more than five years as school leaders, seven were first-time principals. 
Table 2

Schools and their Assigned Principals during 2012-2013 and 2013-2014

\begin{tabular}{lcc}
\hline School & Principal 2012-2013 & Principal 2013-2014 \\
\hline School 1 & Principal A \& Assistant Principal A & Principal A \& Assistant Principal A \\
School 2 & Principal B & Principal C \\
School 3 & Principal D & Principal D / Principal E \\
School 4 & Principal F & Principal G \\
School 5 & Principal H & Principal F \\
School 6 & Principal I / Principal J & Principal J \\
\hline
\end{tabular}

The turnover of leadership at the school sites served as a limitation for this study because perspectives, processes, and efforts toward change varied from principal to principal within a school. Table 2 summarizes the leadership turnover experienced at the schools during the two years of the study. Only one school maintained the same leadership for the two consecutive years of this study. Principal D was removed midyear, and the position was filled by Principal E. Principal F transferred from School 4 to School 5. In School 6, Principal I was removed midyear, so Principal J represents a lead teacher that was assigned to serve in the principal capacity during 2012-2013. Principal J subsequently accepted the official principal position the following year. Thus, as illustrated in Table 2, the leadership in these small rural schools was continuously changing.

Core teachers. To gain an understanding of teachers' perspectives of the changes occurring at each middle school, during the 2013-2014 academic year, the teachers in core subjects of English, math, and science were invited to participate in the study. It is important to note that the schools where data were collected were small. There was only one English teacher, one math teacher, and one science teacher in each school. Twelve teachers participated in interviews. For three of the middle schools, all core teachers participated. At one school two core teachers participated, and one core teacher participated at another school. For the remaining school, no teachers participated due to the uncertainty associated with the midyear change in administration.

Of the 12 teachers, only one was a novice; 11 were veteran teachers with a minimum of 5 years of experience in the classroom. It is important to note, however, that 7 of the 12 teachers were new to their respective schools during 2013-2014. Indeed, in many instances, the principal had deliberately recruited veteran teachers as part of the strategy to change the culture of the school and improve academic achievement.

\section{Data Source and Collection}

Semi-structured interviews were the data source for this study. Questions for both the school leaders and teachers were similar. To gain a sense of experiences, each interview began by asking the participant to describe their professional background. This was followed by perceptions about their school, including general questions about the school, personal and school goals for the year, and the school improvement process. The third set of questions was about the curriculum. For the teachers the questions focused on what they taught; for the school leaders, questions were about their strategies to raise academic standards. The last set of questions related to professional development. Again, teachers were asked about professional development in which they participated; leaders were asked about professional development they provided at their schools.

During both years (2012-2013 and 2013-2014), each principal was contacted by email to schedule a meeting time and place to conduct an interview. Each interview was conducted in the principal's office. For the school with the principal and assistant principal, both leaders were interviewed together. The interviews were approximately 30-60 minutes in length, but most typically lasted 45 minutes. Each interview was audio-recorded and later transcribed verbatim.

During 2013-2014, in addition to scheduling and interviewing school leaders, principals were asked via email to let their core academic teachers know of the study and that the investigators would contact the teachers directly for possible participation in the study. Therefore, during this second year, the school leaders and core teachers who volunteered for the study were interviewed. Teachers were interviewed individually in the privacy of their 
classrooms during their preparation period, so no students or other adults were present. All interviews with core teachers lasted between 20-45 minutes; interviews were audio-recorded and later transcribed verbatim.

\section{Data Analysis}

The data analysis occurred in five phases. First, principal interviews were fully read to identify potential themes. Through this process, it was clear that external mandates and personal perspectives were key filters through which principals thought about what was occurring at the schools to which they were assigned. The second phase consisted of a line-by-line analysis to code the unique themes, as well as to gain clarity and refine the themes.

Following the coding of the data from the principals, the interviews conducted with teachers were analyzed independently. Similar to the principals, external demands and personal perspectives were identified, but they were revealed quite differently than was in evidence in the principal interviews. The fourth step was a line-by-line analysis of the teacher interviews to refine the themes identified at the holistic level. Finally, themes identified in the principal interviews were compared with the themes identified in the teacher interviews. At this stage, investigator triangulation was used to refine the findings. In addition to a thorough review by the research team, themes were presented to many of the participants as a form of member checking.

The findings of this study only apply to the schools of the case studies and are limited to those interviewed. The researchers were familiar with the rural communities and aware of the history of chronic academic stress at the schools, which may have contributed to the analysis.

\section{Findings}

School leaders and teachers interviewed for this study expressed an understanding of the need and a commitment to demonstrate school improvement (i.e., increase student achievement based on state testing), increase morale and collaboration, and develop a culture of improvement (i.e., college-going culture) at their schools. Language used by principals and teachers suggested that they believed these areas were interrelated. School leaders and teachers appeared to actively foster a college-going culture by describing in detail efforts being undertaken at their schools. Principals and teachers equally indicated a need for community and parent involvement, although they frequently noted specific difficulties with parental involvement. All principals discussed implementing some form of Professional Learning Community (PLC) to focus on school improvement needs. Each principal described a strategic, designated time for their teachers to meet as a PLC; teachers generally expressed positive views of PLCs.

Descriptions of activities associated with building a culture for school improvement were evident in all interviews. However, three distinct but interconnected themes related to how interviewees perceived these efforts were identified. The first theme was a misalignment of how school leaders and teachers interpreted efforts to improve the school. The second theme was that demands to improve inflamed an ongoing focus on what was wrong with the school. The third theme was that principals felt they were alone in the process with a heavy weight on their shoulders. Collectively, these themes provided a conceptual framework of how the principals and teachers portrayed their work to turn the school around and develop a college-going culture.

\section{Misaligned Interpretations of Efforts to Improve the School}

Each school leader expressed a genuine optimism about the direction of his or her school. Each portrayed a confidence, some to the point of bravado, that his or her knowledge, experience, and skills more than prepared the individual to tackle the challenges facing the school. They were thankful for increased resources (e.g., Title I, GEAR UP, school improvement initiatives, etc.) that could be used to impact student success and in general agreed with the accountability associated with the additional resources. They carefully described how the additional resources were allocated to support their respective visions for their schools.

The school leaders were optimistic about their teachers' efforts; principals trusted the teachers they hired. In several instances, detailed descriptions were given about how teachers had been recruited to be part of changing the culture of the school. Likewise, many discussed experiences of struggling to fill teacher vacancies in core subject areas and were happy when all positions were filled with teachers they thought were dedicated to student success. Principals differentiated the various capacities of the existing teaching staff; they wanted to provide what they perceived to be relevant professional development in essential areas. 
Another relevant area was that of community relationships. Inferred from the interviews with the principals, the attitudes about the relationship between school personnel and community members revealed a wide range. All recognized the importance of their schools to the rural community; this was often portrayed as the school being the local beacon of stability and future possibilities. Attitudes about the community fell into two general categories, however. Some either felt part of or were working to become community members. They focused on ensuring that parents felt at home at the school. Others voiced almost disdain for the community, arguing that one of the greatest obstacles in raising academic standards was that parents and other community members did not value education. These principals focused their attention on what could be accomplished within the school, almost in spite of the community. In summary, at the time of the interviews, each school leader expressed optimistic confidence that many pieces were in the right place and school improvement would ensue.

Teachers expressed a belief that they were a part of the many necessary pieces to improve the school academically. Indeed, several teachers indicated that they were specifically recruited or uniquely qualified for the needs of the school. In contrast to the school leadership, however, the ongoing external demands, usually described as "district" demands, contributed to a strong sense of demoralization. Some teachers specifically mentioned that they were effective and successful veteran teachers who could impact student achievement, adding a phrase like, if we could just do our job and teach, we would make an impact. They repeatedly expressed feeling overwhelmed with external forms of professional development, few decision-making opportunities about their schools and classrooms, and few options other than to strictly abide by the demand of external forces, with particular pressures from district and state personnel. Of note, the title of this article was a direct quote from one of the teachers, "we feel like we are doing the time for someone else's crime."

School leaders recognized the teachers' hard work and the high demands placed upon them. Many leaders acknowledged that they had minimal control over the focus of their teachers' professional development and other expectations for improvement. Consequently, within their realm, principals seemed to empathize with their teachers. They could acknowledge the demoralization among teachers; however, for the most part, they were committed to changing the culture of the school to be consistent with the external demands. As a result, principals portrayed a sense of optimistic, explaining that time and effort would lead to the desired improvements.

\section{A Focus on the Wrong}

School leaders and teachers alike were almost singularly focused on what was wrong at their schools, repeatedly citing symptoms of failure. It seemed as if principals and teachers perceived that they were only given the option to focus on deficits. The external messages, attempts to support school improvement efforts, and professional development initiatives were interpreted as constant external reminders of lack of achievement. For example, school leaders clearly identified which students were not meeting the standards; English teachers easily discussed how far behind in reading levels their students were. Newly assigned principals were quick to identify the deficiencies they found when they assumed responsibility for the school. Lack of adherence to school district policy under previous administrations was frequently mentioned as a reason for the school to be in trouble academically.

This fixation on what was wrong at the school or with the students made it nearly impossible to identify forms of celebration within the school. In other words, there was a clear lack of celebration and recognition of any form of success. Even when there were signs of improvement, the interpretation was that the improvements were not sufficient.

\section{Feeling Alone with a Heavy Weight}

Despite their optimism, school leaders assigned to the schools included in this study seemed to feel alone in the process of school improvement. When principals were new to a school, a deep commitment to turn around the school was in evidence; however, there was a noticeable lack of recognition on their part of efforts made by previous administrators. It was as if the principal arrived with the belief that he or she had to create a climate of academic achievement from scratch - or he or she was forced to climb out of deep hole.

In addition to expressing the need to be the champion of efforts to redeem the school in the eyes of various stakeholders, they described working endlessly on paperwork. Some principals confessed to arriving at the school at five in the morning and working until midnight. They revealed needing to 
complete a plethora of paperwork, attend district and school leadership meetings, and participate in various forms of professional development with their teachers, as well as with peer leaders. The amount of work was in part related to the fact that all but one of the schools included elementary, middle, and/or high schools. Each level required the same amount of paperwork. As such, for the two combined (K-12) schools, three sets of reports were mandated; the two elementary (K-8) schools required two sets of reports; and the school that was a combined middle and high school also required two sets of reports. Even though, principals made efforts to collaborate with their teachers, build a rapport with students, engage the community, and foster external partnerships, there was still a sense of isolation in the work that had to be completed.

\section{Discussion}

The school leaders and core academic teachers represented in this study appeared to be working hard to turn around their schools and change the culture. Specifically, they articulated messages and fostered activities to achieve the goals at their rural middle schools. The most striking finding of this study was the very different perspectives of the overall state of the school held by the principals and teachers. Principals were optimistic and expressed confidence that they were headed in the right direction-toward increased student achievement and overall school improvement. In contrast, teachers were pessimistic and made statements about being demoralized by all of the external pressures on the school and their lack of autonomy. This lack of alignment is inconsistent with the recommendations of Glickman et al. (2014) that education change theory is based upon a coherent approach and shared leadership.

Several teachers maintained that they were specifically recruited to the school because of their documented abilities as effective teachers; they lamented that external "experts" did not trust them to do their jobs successfully. While these views may have seemed to be individual complaints, such views or beliefs are known to influence a number of school efforts. In particular, “teachers' negative beliefs, behaviors, and emotions about their schools influence their perceptions about teacher collaboration, instructional communication, collaborative leadership, trust, unity of purpose, and professional development" (KaradaĞ, KiliçOĞLu, \& Yilmaz, 2014, p. 107). Mertler (2010) found that teachers overwhelmingly reported that NCLB had negatively impacted their motivation, classroom instruction, and placed more stress on them. Teachers ultimately experienced a sense of demoralization, which is not uncommon in these situations (Santoro, 2011).

There are several explanations for this misalignment between principal and teacher perceptions. One is that the principals may have simply not been confronting reality. Byrd and Brown (2012) examined rural principals' decision-making and the impact on student achievement; they found a "significant misalignment between principal perceptions regarding their use of data to make campus level decisions and the subsequent impact of those decisions on student achievement" (p. 8). After all, over half of the principals in this study were novice educational leaders and most were newly appointed to the schools they led.

Perhaps a more likely explanation aligns the first and third theme identified in the interviews. Principals were optimistic, but they felt they were alone in their effort. Duke and Landahl (2011) found that the principal in their study had a deep commitment to the school to pursue better performance, with the responsibility resting on the principal's shoulders. Similarly, it appears that as leaders of their schools, the principals in the current study felt an obligation to be the positive face of the school. Each had accepted the challenge of turning the school around; this meant that they would be the standard-bearer of the positive.

A third explanation brings in the second theme, the focus on what was wrong at the school. It was particularly noteworthy that the principals were optimistic, yet they focused on the negative indicators at the school and there was a noticeable absence of celebrations in the schools. The history of each school being in chronic academic stress placed repeated pressures on principals and teachers. ByrdBlake et al. (2010) recognized the need to address the external pressures placed upon teachers, especially those working at high-poverty schools. Essentially, principals wanted to lead and teachers wanted to teach, but both groups expressed an inability to do so because of the requirements and mandates that they could not control. All had experienced a loss of autonomy. Indeed, Santoro (2011) reported similar findings. In describing like experiences, a particular teacher "came to believe that 'real teaching,'... became impossible in the context of classroom-level policy interventions" (Santoro, 2011, p. 12).

Overall, despite their seeming incongruity, all three themes appeared to be integrated and likely 
served as compounding factors in how principals and teachers thought about their work. In addition, the principal and teacher turnover must not be overlooked. Most principals were new to the leadership role, and many of the teachers, although veteran educators, were new to the school. When these shifts occurred, there seemed to have been a revived sense of hope, particularly among principals but not the core teachers. Still, there was little time for both groups to acclimate to their new schools, gain trust and buy-in from others, and make autonomous decisions for school improvement. The academic challenges mixed with requirements for principals to quickly adapt to new settings and make immediate improvements are reflective of recent research (Kehoe, 2012; McLester, 2011). Kehoe (2012) found that "principals indicated they were being held to very high and immediate expectations, with 'no honeymoon' period allowed" (p. 92).

\section{Conclusion}

Principals assigned to schools must balance many leadership responsibilities. At a minimum, principals are expected to make sure there are lights and heat in the building. Likewise, schools are often at the center of rural community activities; principals are key to effective school-community relationships. Principals must also provide leadership to ensure that students are academically prepared for their futures; associated standards and expectations continue to rise. When those standards and expectations are set directly from outside of the community, they often complicate school-community relationships. Yet, an ability to strengthen those relationships remains necessary. Furthermore, as instructional leaders, principals are expected to advocate for teachers' time and needs but must also move forward with the vision and mission for school improvement. With rural school teacher shortages increasing, principals at rural schools continue to struggle to recruit and retain teachers (Brenner, Elder, Wimbish, \& Walker, 2015). In essence, effective principals are like skillful jugglers, keeping many balls in the air while talking calmly to an audience!

This juggling act makes it even more pertinent for rural school principals to recognize the potential for misaligned expectations between principals and teachers. When focusing on turnaround efforts at rural schools, Mette (2014) found that building-level leadership mattered. Principals assigned to rural schools cannot be the sole champions for school improvement, but must work to ensure that teachers do not feel demoralized in reform efforts. One way to accomplish this is for principals to be cognizant of the consequences of a collective focus on what is wrong at the school, as found in our study. It is recommended that leaders intentionally identify successes within the school. Successes must then be celebrated in a manner to support the idea of steady improvement. For instance, some type of barometer could be visibly placed to record both a steady progress and a variety of academic improvements.

School district leaders must also be mindful of the potential impact of assigning first-time principals to rural schools that have had chronic academic achievement challenges. It is common in urban schools for principals to gain administrative experience as an assistant principal or other administrator working for an experienced principal. Particularly first-time rural school principals cannot and should not carry the heavy weight and burden on their shoulders alone. When rural district and school leaders collaborate to support school changes, "Both sides must understand the required shift in perspectives, actions, and expectations, not only of themselves but of each other" (Mette, 2014, p. 19). It is important for principals and school district leaders to utilize shared leadership practices that can help to carry out essential goals and involve all stakeholders.

Findings from this study provide insight into how a critical educational policy goal (i.e., changing the academic trajectory of a rural school under chronic academic stress) was interpreted by the individuals who were responsible for carrying out the goal. It is certainly possible to create a college-going culture in rural schools; however, the individuals working in the school must believe that they are part of the building process and not pawns in a chess game in the case of teachers or solo pilots in the case of the principals. If attention is not paid to the individuals who actually work at the school accomplishing laudable goals can be compromised. It is not uncommon for innovations and reform to fade over time, thus leading to concerns of sustainability (Duke \& Landahl, 2011). 


\section{References}

Brenner, D., Elder, A., Wimbish, S., \& Walker, S. (2015). Principals' perceptions about alternate route programs in rural areas. The Rural Educator, 36(2), 38-46. Retrieved from http://epubs.library.msstate.edu/index.php/rural educator/article/view/282

Brown, P., Finch, K., MacGregor, C., \& Watson, R. (2012). Divergent angry voices. International Journal of Educational Leadership Preparation, 7(3), 1-16.

Byrd, J. K., \& Brown, S. (2012). Rural school principals' use of data in data-driven decisionmaking and the impact on student achievement. Education Leadership Review, 13(1), 1-10.

Byrd-Blake, M., Afolayan, M. O., Hunt, J. W., Fabunmi, M., Pryor, B. W., \& Leander, R. (2010). Morale of teachers in high poverty schools: A post-NCLB mixed methods analysis. Education \& Urban Society, 42(4), 450-472.

Cross, T.L., \& Dixon, F.A. (1998). On gifted students in rural schools. NASSP Bulletin, 82, 119-124.

Day, C. (2007). Sustaining the turnaround: What capacity building means in practice.

International Studies in Educational Administration (Commonwealth Council for Educational Administration \& Management (CCEAM)), 35(3), 39-48.

Duke, D. L. (2008). Diagnosing school decline. Phi Delta Kappan, 89(9), 667-671.

Duke, D. L., \& Landahl, M. (2011). 'Raising tests scores was the easy part': A case study of the third year of school turnaround. International Studies in Educational Administration (Commonwealth Council for Educational Administration \& Management (CCEAM)), 39(3), 91-114.

Evans, R. (1996). The human side of change: Reform, resistance, and the real-life problems of innovation. San Francisco, CA: Jossey-Bass.

Finkel, E. (2012). Principals as instructional leaders. District Administration, 48(6), 50-55.

Fullan, M. (2009). The challenge of change: Start school improvement now! (2nd ed.). Thousand Oaks, CA: Corwin.

Glickman, C. D., Gordon, S. P., \& Ross-Gordon (2014). Supervision and instructional leadership: A developmental approach (9th ed.). San Francisco, CA: Pearson.

Karadağ, E., Kiliçoğlu, G., \& Yilmaz, D. (2014). Organizational cynicism, school culture, and academic achievement: The study of structural equation modeling. Educational Sciences: Theory \& Practice, 14(1), 102-113. doi: 10.12738/estp.2014.1.1640

Kehoe, S. L. (2012). Socialization of school improvement grant princpals during the first year of forced leadership change: A retrospective phenomenological study. (Doctoral Dissertation). ProQuest Dissertations \& Theses Global Database. (UMI No. 3539194)

Leithwood, K., Louis, K.S., Anderson, S., \& Wahlstrom, K. (2004). How leadership influences student learning. New York: The Wallace Foundation.

Lynch, J. M. (2012). Responsibilities of today's principal: Implications for principal preparation programs and principal certification policies. Rural Special Education Quarterly, 31(2), 4047.

McLester, S. (2011, May). Turnaround principals: New training models have emerged for preparing school leaders to transform lowachieving schools. District Administrator Magazine. Retrieved from http://www.schoolleadership20.com/forum/topi cs/turnaround-principals-new

Mertler, C. (2011). Teacher's perceptions of the influence of No Child Left Behind on classroom Practices. Current Issues in Education, 13(3). Retrieved from http:/cie.asu.edu/ ojs/index.php/cieatasu/article/viewFile/392/105

Mette, I. (2014). Turnaround reform efforts in a rural context: How community and culture impart change. The Rural Educator, 35(3), 12-21.

Nadelson, L.S., Pulska, H., Moorcroft, S., Jeffrey, A., \& Woodard, S. (2014) Educators' perceptions and knowledge of the Common Core State Standards. Issues in Teacher Education, 22(2), 47-66.

Norwood, J. R. (2007). Professional learning communities to increase student achievement. Essays in Education, 20, 33-42.

Price, H. E. (2012). Principal-teacher interactions: How affective relationships shape principal and teacher attitudes. Educational Administration Quarterly, 48(1), 39-85.

Radcliffe, R., \& Stephens, L. C. (2008). Preservice teachers are creating a college culture for at-risk middle school students. Research in Middle Level Education Online, 32(4), 1-15. 
Santoro, D. A. (2011). Good teaching in difficult times: Demoralization in the pursuit of good work. American Journal of Education, 118(1), $1-23$.

Simmons, J. (2011). To improve schools, stop guessing and start using research. Education Digest, 76(9), 37-39.

U.S. Department of Education, Office of Elementary and Secondary Education. (2006, July 21). LEA and school improvement, non-regulatory guidance. Student achievement and accountability programs. Retrieved from http://www.eric.ed.gov/PDFS/ED493419.pdf. Waters, J. T., Marzano, R. J., \& McNulty, R. A. (2003). Balanced leadership: What 30 years of research tells us about the effect of leadership on student achievement. Aurora, CO: McREL. Witherspoon, D., \& Ennett, S. (2011). Stability and change in rural youths' educational outcomes through middle and high school years. Journal of Youth and Adolescence, 40(9), 1077-1090. doi: 10.1007/s10964-010-9614-6

\section{About the authors:}

Jafeth E. Sanchez, Ph.D. is an assistant professor at the University of Nevada, Reno. Her research includes educational leadership practices, change efforts, and educational outcomes in both K12 and higher education settings. Much of her work is focused on developing high quality school leaders.

Janet Usinger, Ph.D. is an associate professor at the University of Nevada, Reno. Her research and evaluation interests focus on perceptions, understanding relationships that individuals hold regarding the educational institutions with which they are affiliated.

Bill W. Thornton, Ph.D. is an associate professor at the University of Nevada, Reno. His research interests focus on program evaluation, systems thinking, organizational theory, and educational leadership.

William Sparkman, Ph.D. is a professor at the University of Nevada, Reno. His research expertise has focused on issues in education law and school finance. 